\title{
Seismic strain and stress field studies in Italy before and after the Umbria-Marche seismic sequence: a review
}

\author{
Silvia Pondrelli and Andrea Morelli \\ Istituto Nazionale di Geofisica e Vulcanologia, Sezione di Bologna, Bologna, Italy
}

\begin{abstract}
The seismic sequence that hit Umbria and Marche during 1997 and 1998 was particularly significant because it dramatically marked the evolution of analysis tools and the development of our geophysical knowledge of the region. Since September 1997, we have had a growing, coherent catalogue of source moment tensors that provides reliable information on earthquake sources in Italy and the surrounding regions. Together with borehole and other tectonic data, this has conspicuously improved our knowledge of the regional strain and stress fields. The main impact of these new data that include local information consists of the possibility to change the scale of the regional geodynamic frame. The simple description of extension tectonics that dominate the Apennines belt has evolved into the present-day maps of the strain and stress fields, where the active tectonics involve compression in the eastern Alps, extension and compression fronts in the northern Apennines, extension and strikeslip structures in the southern Apennines, and a compressional front along the southern Tyrrhenian Sea. This recent geodynamic evolution and the present-day seismotectonic sketch of the Italian peninsula are here described on the basis of the recognition of these tectonic features.
\end{abstract}

Key words seismic deformation - stress field - centroid moment tensor

\section{Introduction}

The Mediterranean region and the Italian peninsula at its core are strongly seismic areas. Their peculiar geodynamic characteristics have been extensively studied over the past 30 years or so, using a broad range of observations and techniques, including geological and geophysical studies. Indeed, the central Mediterranean region is a crucial section of the tectonic bound-

Mailing address: Dr. Silvia Pondrelli, Istituto Nazionale di Geofisica e Vulcanologia (INGV), Sezione di Bologna, Via Donato Creti 12, 40128 Bologna, Italy; e-mail: pondrelli@bo.ingv.it ary between the slowly converging Eurasia and Africa plates (McKenzie, 1972; Dewey et al., 1989). This region is believed to be at the quasifinal stage of a process that involves subduction and continental collision, which has built up the wide Alpine belts, and which started in the Late Cretaceous and continues today (Faccenna et al., 2001). The roughly N-S compressional system acted approximately at the same time as the opening of the Tyrrhenian basin, starting in the Late Tortonian (fig. 1; Patacca and Scandone, 1989). The extensional process and the coeval formation of the Apennines are related to the subduction system that has been active over the last $20 \mathrm{Ma}$ along a front that runs from Sicily to the northern Apennines. Tomographic images show the nearly continuous subducting Adria plate below the Apennines (Lucente et al., 1999; Piromallo and Morelli, 2003). The Tyrrhenian Sea-Apennines system evolved somewhat more 


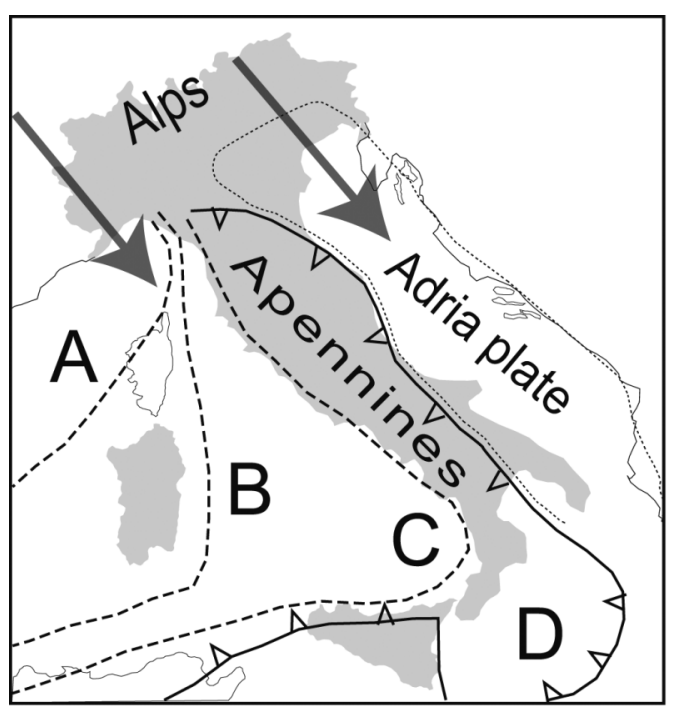

Fig. 1. Sketch of the geodynamic evolution of the Italian region. Dashed lines indicate the approximate position of the Apennines front - and coeval opening of the Tyrrhenian Sea - at A (20 Ma), B (10 Ma), C (1 Ma) and the actual position (D) according to the paleotectonic reconstruction by Faccenna et al. (2001). Line D has a hatches pattern with the direction corresponding to the subduction dip and represents the present-day location of the convergent boundary. The dotted line indicates the boundary of the Adria plate. Large arrows indicate the presentday convergence direction between the Africa and Eurasia plates (DeMets et al., 1994).

rapidly than the convergence between Africa and Eurasia (Malinverno and Ryan, 1986; Faccenna et al., 2001), which indicates that driving forces different from macroplates motion may have been important.

This complex evolution was the origin for all the different tectonic styles acting at the same time in this region: compressive deformation along the eastern Alps and in the southern Tyrrhenian; extension along the entire Apennine belt; and, although less relevant, strike-slip deformation related to transfer structures, such as those in the southern Apennines. A map of this heterogeneous geodynamic framework has become possible due to the increased quantity and density of the more recently available data.
The relevance of the Umbria-Marche seismic sequence was not in the sheer size of the earthquakes, although the several events of magnitude greater than 5.5 that shook an entire region for several months cannot be easily forgotten. The relevance is mainly that the scientific community responded strongly, showing the abilities acquired over years of study. For the first time, extensive sets of high-quality data were collected rapidly, and used rapidly as well, to describe the evolution of the seismic sequence (e.g. moment tensor computations; Ekström et al., 1998; Morelli et al., 2000).

In the present study, we review the status of our knowledge about the stress and strain fields in Italy before and after 1997, to show how the occurrence of the Umbria-Marche seismic sequence and the following surveys improved our view of the situation. We describe the scale of observations in the past and its increment with time, and the consequent improvements to our knowledge of the geodynamic state of the central Mediterranean.

\section{Seismic strain and stress field studies before 1997}

Moment tensor summation techniques (Kostrov, 1974; Jackson and McKenzie, 1988; Ekström and England, 1989; Westaway, 1992) have allowed the quantitative evaluation of the distributed deformation due to seismic activity. The basic equation to determine the average strain is:

$$
\overline{\varepsilon_{i j}}=\frac{1}{2 \mu V} \sum_{k=1}^{N} M_{i j}^{k}
$$

where $\mu$ is the shear modulus, and the sum of the moment tensor elements $M_{i j}$ is taken for all of the $N$ earthquakes located within the volume $V$.

On the basis of this analysis, the summary geometric characters of seismic activity can be evaluated and integrated over time, along with the importance of the seismic strain relative to the overall deformation along the main active zones. Cumulative strain can usually be plotted in different ways: as a focal mechanism, or showing the $P$ and $T$ axes, e.g. the eigenvectors, of the cumulative moment tensor. Cumulative 
moment tensors have been calculated over the entire Mediterranean region since the 1980's (e.g. Jackson and McKenzie, 1988), using data of the strong seismic activity that characterizes the region and the consequently larger dataset that has become available time by time. For the relevant seismicity that characterized the Italian region, at that time, Jackson and McKenzie (1988) could only use the information coming from seven earthquakes, five of which were along the Apennine belt and two in Sicily (fig. 2 ). They averaged the effects of these seismic events within long straight boxes that included the active tectonic boundary under study. From these quite sparse data, it was however possible to describe the main features of the seismic deformation, such as the extension occurring along the Apennines, and the compression characterizing the Africa-Eurasian boundary running from the Gibraltar Straits across Sicily. The computed strain was much smaller than expected, hinting at the presence of a large amount of aseismic strain. Less than 10 years later, Pondrelli et al. (1995) recomputed the seismic strain for the entire Mediterranean region, when the larger centroid moment tensor (CMT) dataset became available (Dziewonski et al., 1981; Dziewonski and Woodhouse, 1983; fig. 2). In Italy, there were about twice as many focal mechanisms as in Jackson and McKenzie (1988). The deformation calculated for the same boxes representing seismogenic zones confirmed the styles of deformation detected by Jackson and McKenzie (1988) for the two different time intervals considered (16 and 85 years). Pondrelli (1999) applied the same moment tensor summation technique over regions that were smaller than the boxes used before. This denser dataset (fig. 2) that covered about 90 years was increased through the collection of data for older earthquakes and the addition of moment tensors of events that had occurred in the meantime. This larger dataset allowed to do a finer partitioning of the active tectonic boundaries. As a result, in addition to the known extension along the Apennines, a similar trend was also found in Calabria. Compression was revealed in the eastern Alps and Sicily. Along the Africa-Eurasian boundary, which had generally been considered to be homogeneously in

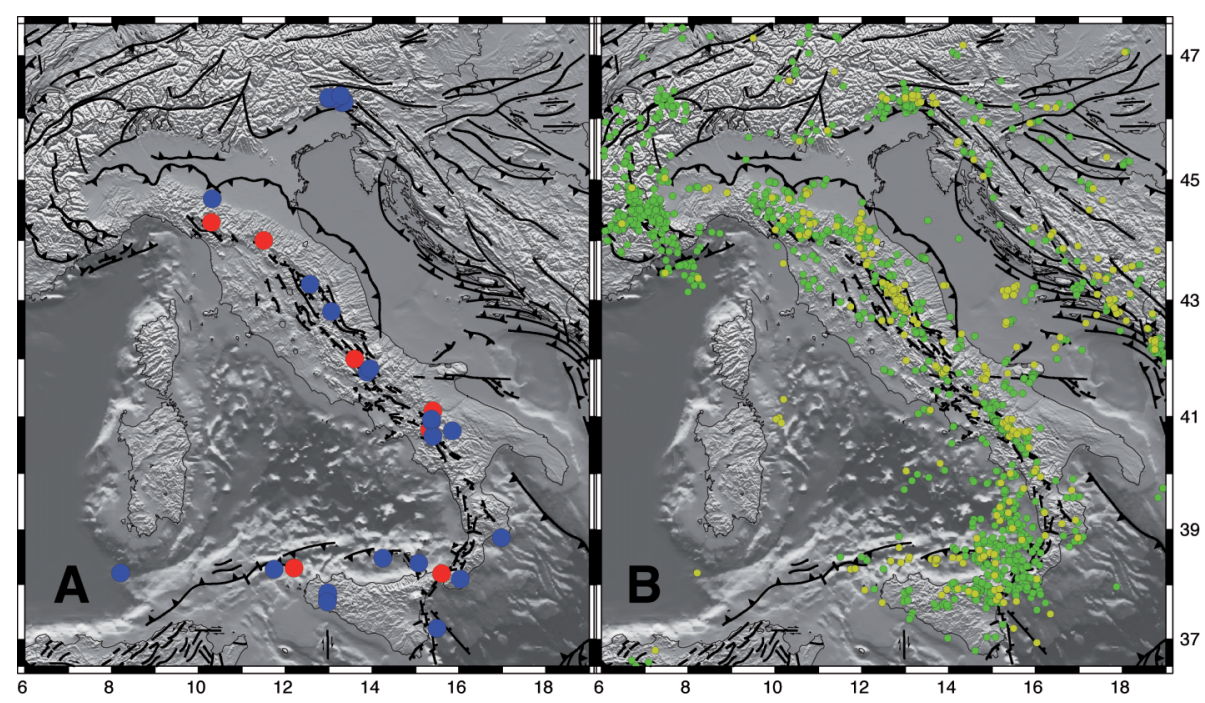

Fig. 2. Maps showing the growing number of earthquakes used as information to study strain and stress fields over the last 30 years. A) red: data from Jackson and McKenzie (1988); blue: data added by Pondrelli et al. (1995) and Pondrelli (1999). B) yellow: data from CMT and RCMT catalogues; green: data coming from the EMMA Database 2.0 (Vannucci and Gasperini, 2004). 
compression, alternate compression and transpression were detected.

Besides showing maps of the main styles of deformation that act in the central Mediterranean region, studies carried out in the 1980's to 1990 's also provided quantitative evaluations of the amount of strain. The seismic strain could then be compared with the velocities obtained from plate motion models (Argus et al., 1989; De Mets et al., 1994). Taking into account that the result of moment tensor summation is obviously only representative for the time interval of the earthquakes included and the dimension of the volume of crust considered, the most relevant observation that stemmed from this comparison was that the seismic strain is generally smaller than the plate motion expectations. In the Italian region, large scale plate motion models cannot be used, because they do not represent micro-plate motion, as for Adria. Consequently, all comparisons have been carried out using predicted strain rates obtained by other kinematic and geological studies (Pondrelli et al., 1995; Jackson and McKenzie, 1988; Westaway, 1992) and the results have been considered as the only being possible, and underestimated, evaluations.

Only since the 1990's the data that describe the state of stress in the crust have been grouped and widely used to map and study the active stress field, and to understand its relation to the geological features (e.g. Zoback, 1992). For this purpose, the following stress indicators are used: focal mechanisms of strong earthquakes (obtained by first-arrival analysis, and when possible, by waveform modelling) and composed or averaged focal mechanisms for earthquakes of moderate to small magnitudes; well bore breakouts; in-situ stress measurements, such as hydraulic fracturing, overcoring; young geological data, such as fault-slip data, and volcanic alignment. The World Stress Map (Zoback, 1992) adopts the assumption that since no shear stress can exist on the plane of the Earth's surface, one of the main stress axes in the crust must be vertical (Anderson, 1951). As a consequence, stress maps report the direction of horizontal stress, in general as $\mathrm{S}_{\mathrm{Hmax}}$ (the maximum horizontal stress axis; Zoback, 1992). The active stress field for the Italian region reported in the first version of the World Stress Map was poorly constrained due to the scarcity of data (fig. 3). In-situ measurements were available for Sicily only, and the situation of focal mechanisms was the same as that described previously relating to seismic strain studies. The scarcity and heterogeneity of the dataset was also the reason why the interpolated map of the stress field in the Mediterranean region compiled by Rebaï et al. (1992) was particularly weak. Indeed, the interpolated grid has elements that are much smaller than the average spacing of the data, and most of the knots of the map are not actually related to any data. However, some of the characteristics of the stress field have been recognized, as for instance the extensional regime affecting the Apennines, although it was severely smoothed and consequently reported only in a sketch of the entire Mediterranean region.

\section{The Umbria-Marche seismic sequence: regional seismic moment tensors and focal mechanisms}

The Umbria-Marche earthquake sequence marked the beginning of a period of extensive collection of new geophysical data for the Italian region. Significant improvements have been made to the moment tensor calculations and the focal mechanism collections, and also to the study of historical seismogenic sources (e.g. the Database of Individual Seismogenic Sources; http://www.ingv.it/DISS) and to the borehole breakout measurements. At that time, the routine determination started for seismic source parameters by long-period waveform fitting, which continues today. The technique to compute the moment tensors for moderate-magnitude earthquakes uses a modification of the algorithm known as the CMT (Dziewonski et al., 1981), as applied to the modeling of intermediate-period surface waves recorded at regional distances. Harvard/Global CMTs are routinely calculated for $\mathrm{M}>5.5$ at the global scale, and the CMT catalogue represents the best known and most reliable reference for seismic source parameters in the seismology community (Dziewonski and Woodhouse, 1983; Dziewonski et al., 2001, and references therein). Standard 


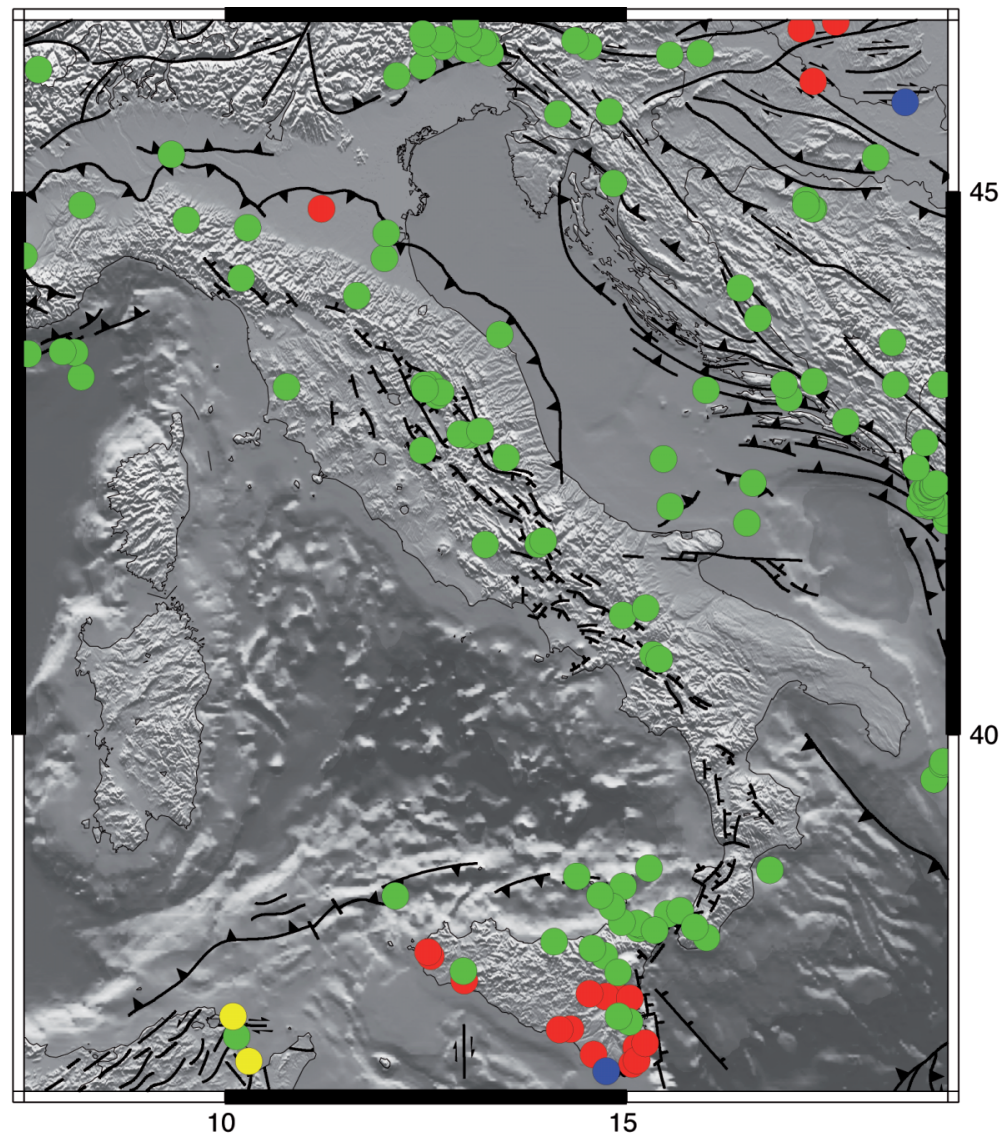

Fig. 3. Map showing the data of the first version of the World Stress Map (Zoback, 1992) for the Italian region. Different colours indicate different kinds of data. Green: focal mechanisms, composite, averaged or of a single earthquake. Red: borehole breakouts. Blue: overcoring data. Yellow: geologic fault-slip data (inversions or paleo-focal mechanisms).

CMTs are obtained by fitting long-period body waves, together with long-period ( $\mathrm{T}>135 \mathrm{~s}$ ) surface waves only for large magnitude events. For moderate-magnitude events, long-period waves generally have small signal-to-noise ratios, such that reliable inversion is not possible. On the other hand, at shorter periods, surface waves represent the most evident wave trains at regional distances, even for moderate magnitudes. These waves are, however, highly influenced by the lateral heterogeneity of the Earth's structure, and their use without an accurate account of it would produce results that are biased by unmodelled wavefield propagation effects. The approach followed to obtain Regional CMTs (RCMTs) therefore computes and fits synthetic seismograms for Love and Rayleigh surface waves with periods between $35 \mathrm{~s}$ and 60 $\mathrm{s}$, using detailed phase velocity maps developed with high resolutions at the global scale (Arvidsson and Ekström, 1998).

RCMTs were calculated for the first time for the Umbria-Marche seismic sequence, for more than 40 events that occurred between the autumn of 1997 and the summer of 1998 and had magnitudes between $\mathrm{M}_{\mathrm{w}} 4.5$ and 6.0 (Ekström et al., 
1998; Morelli et al., 2000; Pondrelli et al., 2002). As the seismic sequence was going on and new solutions were constantly computed, the remarkable coherence among all of the mechanisms became quite striking. All of the moment tensors showed extensions along a NE-SW direction, which was confirmed by other studies on the earthquakes (fig. 4). Only one event showed a strike-slip mechanism, but its difference from all of the other events of the sequence also included its larger focal depth, of about $50 \mathrm{~km}$.

The situation has evolved considerably during this past decade. Since 1997, source parameters for more than 600 earthquakes in the European and Mediterranean regions have been computed, and more are being included regularly into a coherent catalogue (Pondrelli et al., 2002; 2004a; 2007), which is also accessible on the worldwide web at www.bo.ingv.it/RCMT (fig. 2). Moreover the Italian subset of RCMTs has been extended in time, going backwards as long as possible according to the data require- ments, so that it includes earthquakes from 1977 to the present (Pondrelli et al., 2006; www.bo.ingv.it/RCMT/Italydataset). At present, for each earthquake with a magnitude between 4.5 and 5.5 (larger events can also be modeled, but they are always analysed within the Global CMT project) in the European and Mediterranean regions, a fast solution is computed using seismogram data that are available in near-real time (QRCMT) and is published online (http://mednet.rm.ingv.it/quick_rcmt.php). These solutions are then revised when more seismograms are available through data centers (MEDNET, ORFEUS, IRIS). The final solutions are published in the literature and on the dedicated web pages. The number of earthquake source mechanisms per year has increased with time as the minimum magnitude threshold has decreased, in many cases down to about $\mathrm{M}_{\mathrm{w}}=4.0$. This is possible by virtue of the increased availability of broad-band seismographic data at epicentral distances of a few hundred kilometres.

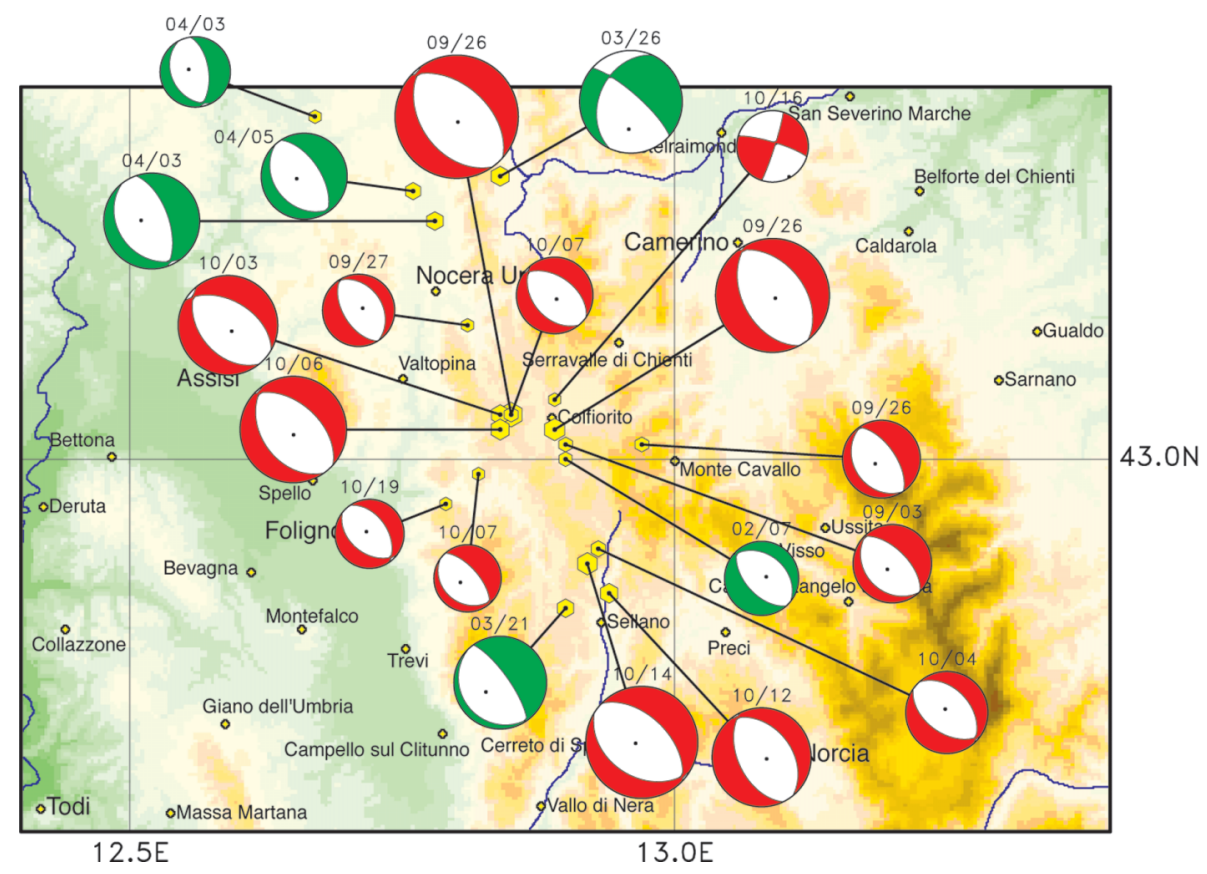

Fig. 4. Map showing the RCMTs computed for the Umbria-Marche seismic sequence. Red: RCMTs for events occurred during September-December 1997; green: those occurred in 1998 (after Morelli et al., 2000). 
Some of the source mechanisms of the events of the Umbria-Marche earthquake sequence have been calculated with as few as three stations. At present, instead, even a fast QRCMT generally results from analysis of about 10 stations, and final solutions are based on data from up to 30 stations. Of course, the geographical location of the event largely determines how good its data coverage is, especially for smaller magnitude events that are not well recorded beyond a few hundred kilometers. A uniform azimuthal coverage is actually the most critical factor.

The creation of the Earthquake Mechanisms of the Mediterranean Area (EMMA) database (Vannucci and Gasperini, 2004) has improved the access to focal mechanisms data. The EMMA database is a collection of all of the focal mechanisms of earthquakes that have occurred in the Mediterranean region and that have been reported only in the literature (fig. 2). That means tens of thousands of rapidly selectable data that can be used for several purposes.

\section{Seismic strain and stress fields after 1998}

The Umbria-Marche seismic sequence triggered vigorous research activity. The large collection of new data allowed the revision of tectonic analyses of Italian and surrounding regions, and added a lot of information to the knowledge outlined in previous publications.

The improvement of the moment tensor dataset has enabled application of the moment tensor summation to grids much smaller than the large straight boxes that had been used in the past. This in turn has allowed a description of the seismic strain patterns also for regions characterized by diffuse deformation rather than only for the boundaries of large rigid plates (Vannucci et al., 2004; Serpelloni et al., 2007). These studies have defined the styles of the seismic deformation in Italy and surrounding regions (fig. 5) on a grid from $1^{\circ} \times 1^{\circ}$ down to $0.5^{\circ} \times 0.5^{\circ}$. All of the moment tensors and focal mechanisms included in on-line catalogues and in the EMMA database have been used, with their separation into different depth layers (Vannucci et al., 2004; http://ibogfs.df.unibo.it/user2/paolo/www/startup.html). The Frohlich ternary diagram
(Frohlich, 1992; 2001) is a red-green-blue (RGB) colour function that is used to identify the prevailing tectonic style in each element of the grid. The cumulative moment tensor obtained for each cell is located in the Frohlich ternary diagram and is subsequently related to a colour that results from a combination of the three main RGB colours, where red represents a compressive regime, green a strike-slip regime, and blue an extensional regime (fig. 6). This analysis shows that along the Apennines, the extensional regime is continuous along the northern arc and in the southern section of the chain; these two parts are separated by a region where the strike-slip regime dominates over the extensional, which is present as well. The extensional deformation strictly follows the highest elevation of the belt, while the outer part is often affected by compressional to strike-slip regimes, although less continuously. No dominant regimes appear along the western and central Alps. In the south, off the northern coast of Sicily, a constant compressive deformation affects the southern Tyrrhenian Sea up to the Aeolian Islands, close to the Messina Strait (fig. 6). Some evident compression is also well represented in the middle of the Adriatic Sea, a region that was considered aseismic for a long time, in its behaviour as a rigid plate, although it is now believed to be a place of diffuse deformation. Similar results (Jenny et al., 2006) have been obtained for the southernmost part of Italy using an irregular grid and the strain determination method of Haines and Holt (1993). Improvements in the acquisition and elaboration of GPS data over the last decade have produced high definition geodetic strain-rate fields. In several reports, focal mechanisms, geodetic and geological data have been combined together to form a joint picture (Kreemer et al., 2001; Jenny et al., 2006; Serpelloni et al., 2007). Usually, the addition of geological information to seismological data is necessary to lengthen the time span over which the strain rate is evaluated, to control the problem that seismic catalogues are too short with respect to the recurrence times of earthquakes and cannot represent the average long-term seismic rate (Jenny et al., 2004).

The production of an active stress map of Italy (Montone et al., 1999; 2004) represented a 


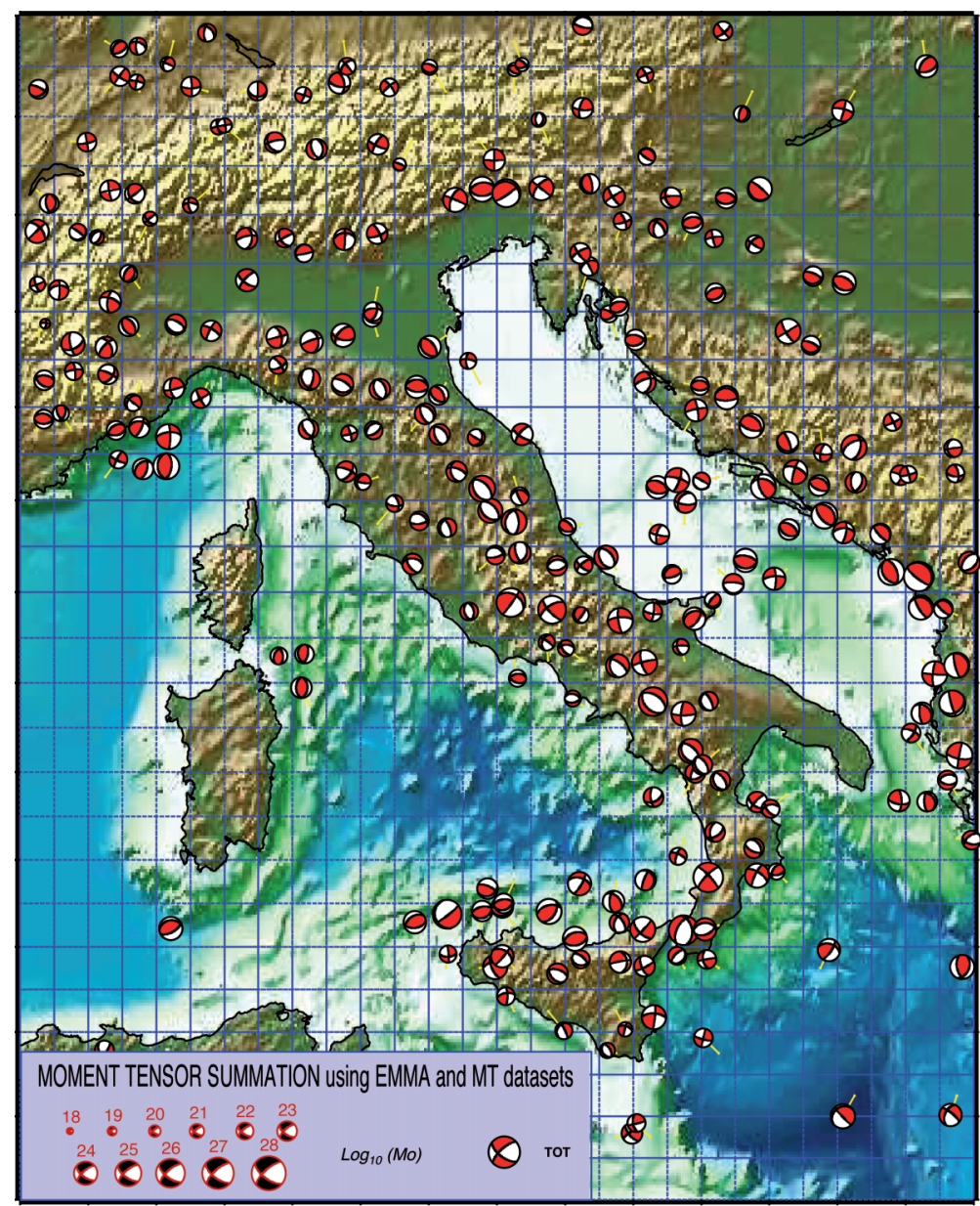

Fig. 5. Map showing the cumulative moment tensors on a regular grid with a mesh of half a degree, for earthquakes with a depth $<50 \mathrm{~km}$ (after Vannucci et al., 2004).

significant improvement over our previous knowledge. This is the instrument that was used to observe some of the most interesting features of the geodynamic framework of Italy, which are sometimes still under discussion. To draw up these maps, all of the indications described for the World Stress Map (Zoback, 1992) have been followed. However, as an extensional regime prevails in the Italian region, $\mathrm{Sh}_{\min }$ (the minimum horizontal stress axis) has been mapped rather than the $S_{H \max }$ used in the World Stress Map. The first version of the active stress map of Italy (Montone et al., 1999) benefited from about 200 horizontal stress directions, 109 from borehole breakouts (available through the elaboration of data provided by oil companies, such as ENI-AGIP), 78 from fault-plane solutions (44 CMTs, 34 other focal mechanisms), seven from stress inversions from microearthquakes, two from averaged T and $P$ axes from events that occurred in areas characterized by diffuse seismicity, and four from active fault data. The entire dataset has reached nearly 400 horizontal stress directions in the most re- 


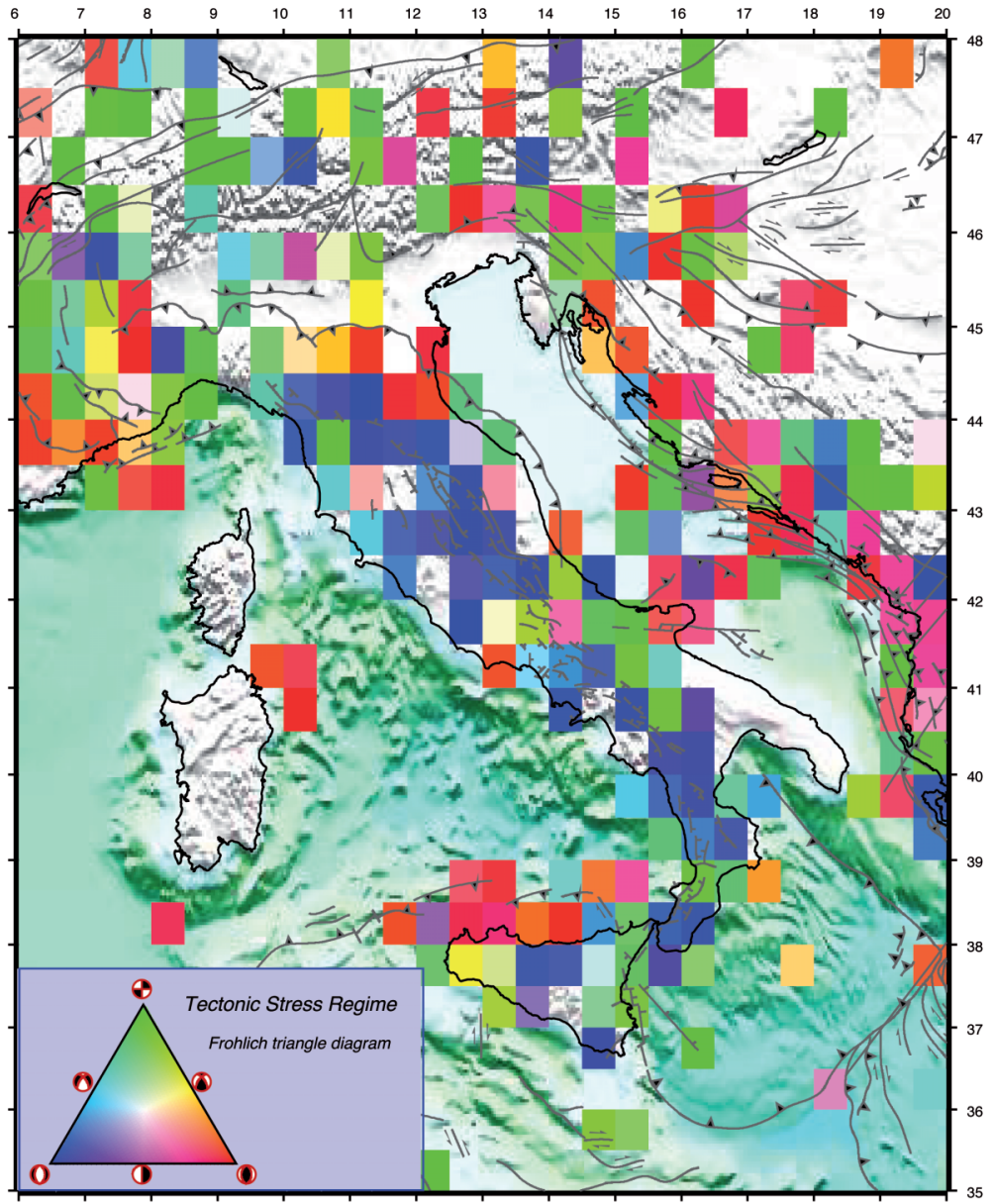

Fig. 6. Map showing the tectonic regime obtained using cumulative moment tensors, plotted following the Frohlich ternary diagram associated to a RGB representation. The data usêd to compute the cumulative moment tensors are the same as those of fig. 5 .

cent version of the map (Montone et al., 2004), where the $61 \%$ is due to borehole breakouts, $38 \%$ earthquake data, and $1 \%$ fault data. This extensive dataset has allowed a reliable smoothed map of the stress field active along our peninsula to be drawn up (fig. 7). Comparing the Rebaï et al. (1992) map with this more recent one, it is possible to see how the larger number and density of the data allows the identification of some changes in the horizontal stress direction that were lost in the past. The most astonishing feature is, however, the rota- tion of the minimum horizontal stress in the outer part of the central Apennines belt (fig. 7), which can be related to the compression also identified on the seismic strain field maps and here inferred also from borehole data.

\section{Conclusions}

The seismological strain data available before 1997 were only a few moment tensors from the CMT catalogue (and were available 


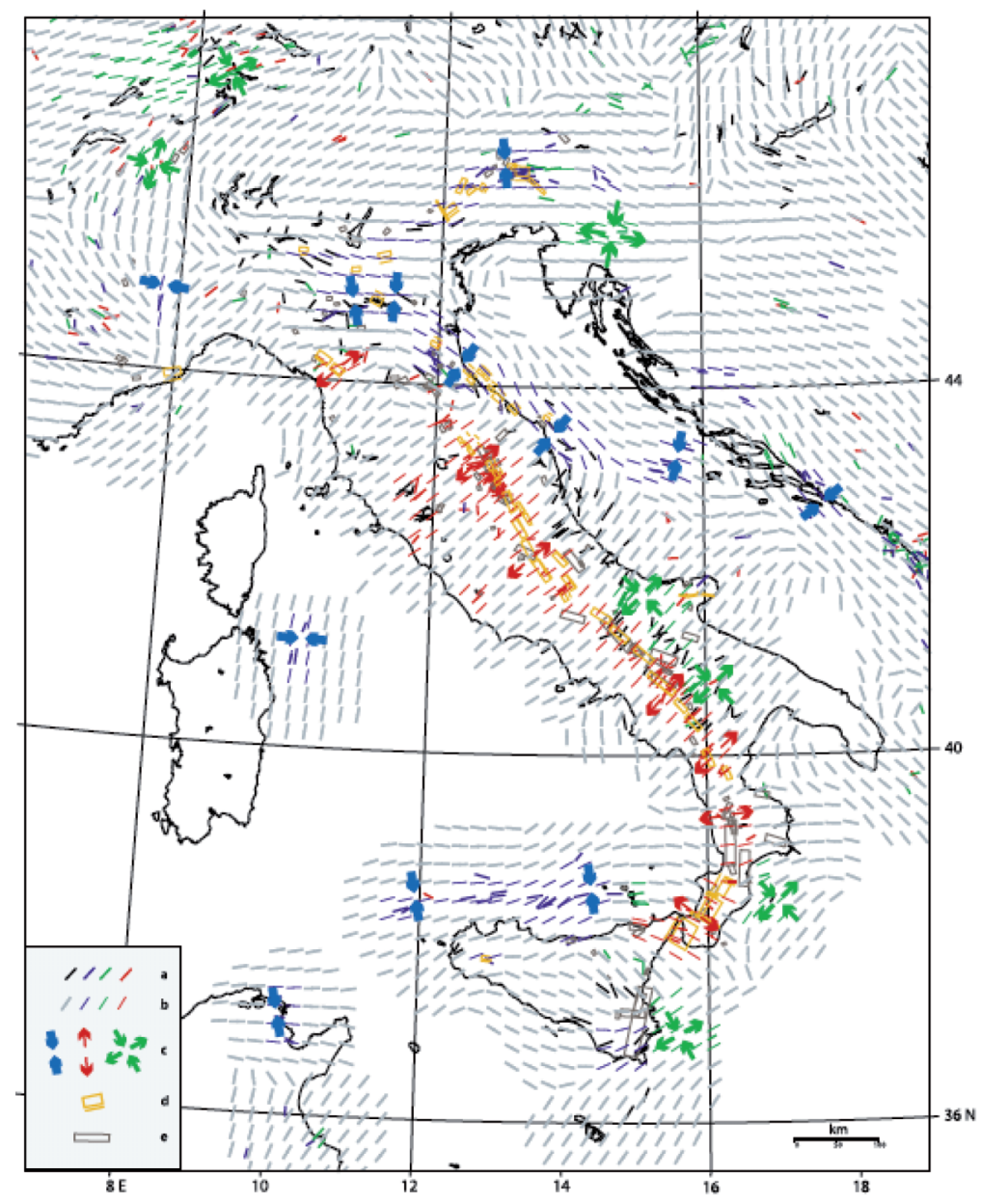

Fig. 7. Smoothed $\mathrm{Sh}_{\min }$ orientation and stress regime of the Italy region. a) $\mathrm{Sh}_{\min }$ directions from our dataset and the World Stress Map 2003 release (colours show different tectonic regimes: black is unknown, blue is compressional, green is strike-slip, and red is extensional); b) smoothed stress directions (colours as before); c) directions of inferred regional stress regimes (colours as before); and d) and e) integrated seismogenic sources from geological/ geophysical (yellow) and well constrained historical (grey) data (after Montone et al., 2004).

only for earthquakes that occurred after 1977 and with an $\mathrm{M}_{\mathrm{w}}$ greater than 5.5) and focal mechanisms from first-arrival determination or source modeling. Tectonic data (such as fault geometry and slip rate) and in-situ measurements needed to be added to draw the first sketches of strain and stress field trends. The addition of a considerable amount of data that was related to an evolution of the determination techniques and seismological data acquisition, built up a reliable dataset for the Italian peninsula and surrounding regions. Now, the moment tensors from CMT and RCMT catalogues, the focal mechanisms included in the EMMA database, the increased borehole breakout dataset and the DISS database, which includes a large number of possible seismogenic sources, make our seismic strain and stress field maps rich in 
information at a scale smaller than in the past. While in the 1980's it was already clear that the main trend of deformation for the Apennine belt was extensional, only later on it was possible to map the compression active in the outer, eastern, part of the chain. This observation, e.g. the co-existence of extension and compression along the mountain chain, is fully consistent with the hypothesis that the Apennines formed after a process of slab retreat and trench migration; this dynamic system would explain why the fast opening of the Tyrrhenian Sea occurred within the Eurasia-Africa collisional boundary. Another example of the importance of the results obtained by strain and stress studies is that for a long time the Tyrrhenian Sea had been considered to be in extension, due to its evolution as a back-arc basin. Only in the last 15 years has compression been mapped along the offshore northern coast of Sicily, where extension was instead expected. Besides the hypotheses that may justify this deformation (Hollenstein et al., 2003; Pondrelli et al., 2004b; D’Agostino and Selvaggi, 2004), what needs to be stressed in particular here is that the increases in the availability of data and the decreases in the scale of observations has led, as a rule, to new ideas.

\section{Acknowledgements}

The authors would like to acknowledge discussions with many colleagues. Figures 5 and 6 were drawn by the work of Gianfranco Vannucci. Data used to prepare figs. 2 and 7 were made available to us by Maria Teresa Mariucci and Paola Montone.

\section{REFERENCES}

ANDERSON, E.M. (1951): The Dynamics of Faulting (2nd. ed.), (Oliver \& Boyb, Edinburgh), pp. 208.

Argus, D. F., R. G. Gordon, C. DeMets and S. Stein (1989): Closure of the Africa-Eurasia-North America plate motion circuit and tectonics of the Gloria fault, $J$. Geophys. Res., 94, 5585-5602.

ARvidsson, R. and G. EKSTRÖM (1998): Global CMT analysis of moderate earthquakes $\mathrm{M}_{\mathrm{w}}>4.5$ using intermediate period surface waves, Bull. Seismol. Soc. Am., 88, 1003-1013.

D'Agostino, N. and G. Selvaggi (2004): Crustal motion along the Eurasia-Nubia plate boundary in the Calabrian arc and Sicily and active extension in the Messina Straits from GPS measurements, J. Geophys. Res., 109, B11402.

DeMets, C., R. G. Gordon, D. F. Argus and S. Stein (1994): Effect of recent revisions to the geomagnetic time scale on estimates of current plate motions, Geophys. Res. Lett., 21, 2191-2194.

Dewey, J. F., M. L. Helman, E. Turco, D. H. W. Hutron and S. D. KNotT (1989): Kinematics of western Mediterranean, in Alpine Tectonics, edited by M. P. Coward, D. Detrich, and R. G. PArk, Geol. Soc. Spec. Publ., 45, 265-283.

Dziewonski, A. M., T. A. Chou and J. H. Woodhouse (1981): Determination of earthquake source parameters from waveform data for studies of global and regional seismicity, J. Geophys. Res., 86, 2825-2852.

DzIEWOnski, A. M. and J. H. Woodhouse (1983): An experiment in the systematic study of global seismicity: Centroid-Moment Tensor solutions for 201 moderate and large earthquakes of 1981, J. Geophys. Res., 88, 3247-3271.

DzIEWONSKI, A. M., G. EKSTRÖM and N. N. MATERNOvSKAYA (2001): Centroid-Moment Tensor solutions for April-June 2000, Phys. Earth Planet. Inter., 123, 114.

EkströM, G. and P. ENGLAND (1989): Seismic strain rates in regions of distributed continental deformation, $J$. Geophys. Res., 94, 10231-10257.

Ekström, G., A. Morelli, E. Boschi and A.M. DziewonsKI (1998): Moment tensor analysis of the central Italy earthquake sequence of September-October 1997, Geophys. Res. Lett., 25, 1971-1974.

Faccenna, C., T. W. Becker, F. P. Lucente, L. Jolivet and F. RossetTI (2001): History of subduction and back-arc extension in the central Mediterranean, Geophys. J. Int., 145, 809-820.

Frohlich, C. (1992): Triangle diagrams: ternary graphs to display similarity and diversity of earthquake focal mechanisms, Phys. Earth Planet. Inter., 75, 193-198.

FroHLICH, C. (2001): Display and quantitative assessment of distributions of earthquake focal mechanisms, Geophys. J. Int., 144, 300-308.

Haines, A. J. and W.E. Holt (1993): A procedure for obtaining the complete horizontal motions within zones of distributed deformation from the inversion of strain rate data, J. Geophys. Res., 98, 12057-12082.

Hollenstein, C., H.-G. Kahle, A. Geiger, S. Jenny, S. Goes and D. Giardini (2003): New GPS constraints on the Africa-Eurasia plate boundary zone in southern Italy, Geophys. Res. Lett., 30, 1935-1939.

Kostrov, V.V. (1974): Seismic moment and energy of earthquakes and seismic flow of rocks, Izv. Acad. Sci. USSR, Phys. Solid Earth, 1, 23-40.

Kreemer, C., W.E. Holt and A. J. Haines (2001): The global moment rate distribution within plate boundary zones, in Plate Boundary Zones, AGU Monograph Series.

JACKSON, J. and D. MCKenZIE (1988): The relationship between plate motions and seismic moment tensors, and the rates of active deformation in the Mediterranean and Middle-East, Geophys. J. Int., 93, 45-73.

Jenny, S., S. Goes, D. Giardini and H.-G. Kahle (2004): Earthquake recurrence parameters from seismic and 
geodetic strain rates in the eastern Mediterranean, Geophys. J. Int., 157, 1331-1347.

Jenny, S., S. Goes, D. Giardini and H.-G. Kahle (2006): Seismic potential of southern Italy, Tectonophys., 415, 81-101.

Lucente, F. P., C. Chiarabba, G. B. Cimini and D. GiardiNI (1999): Tomographic constraints on the geodynamic evolution of the Italian Region, J. Geophys. Res., 104, 20307-20327.

Malinverno, A. and W. B. F. Ryan (1986): Extension in the Tyrrhenian Sea and shortening in the Apennines as a result of arc migration driven by sinking of the lithosphere, Tectonics, 5, 227-245.

McKenzIE, D. (1972): Active tectonics of the Mediterranean region, Geophys. J. R. Astron. Soc., 30, 109-185.

Montone, P., A. Amato and Pondrelli S. (1999): Active Stress Map of Italy, J. Geophys. Res., 104, 2559525610.

Montone, P., M. T. Mariucci, S. Pondrelli and A. AmaTO (2004): An improved stress map for Italy and surrounding regions (central Mediterranean), J. Geophys. Res., 109, doi:10.1029/2003JB002703.

Morelli, A., G. EKSTRÖM and M. Olivieri (2000): Source properties of the 1997-1998 central Italy earthquake sequence from inversion of long period and broadband seismograms, J. Seismol., 4, 365-375.

PataccA, E. and P. Scandone (1989): Post-Tortonian mountain building in the Apennines. The role of passive sinking of a relic lithospheric slab, in The Lithosphere in Italy: Advances in Earth Science Research, edited by Boriani et al., pp. 157-176, Accad. Naz. Dei Lincei, Rome, Italy.

Piromallo, C. and A. Morelli (2003): P-wave tomography of the mantle under the Alpine-Mediterranean area, J. Geophys. Res., 108, 2065-2093.

Pondrelli, S., A. Morelli and E. Boschi (1995): Seismic deformation in the Mediterranean area estimated by moment tensor summation, Geophys. J. Int., 122, 938-952.

PondRELl, S. (1999): Pattern of seismic deformation in the Western Mediterranean, Annali di Geofisica, 42, 57-70.

Pondrelli, S., A. Morelli, G. Ekström, S. MazzA, E.
Boschi and A.M. DzIEwonski (2002): EuropeanMediterranean Regional Centroid-Moment Tensors: 1997-2000, Phys. Earth Planet. Int., 130, 71-101.

Pondrelli, S., A. Morelli and EkströM, G. (2004a): European-Mediterranean Regional Centroid Moment Tensor catalogue: solutions for years 2001-2002, Phys. Earth Planet. Int., 145, 127-147.

Pondrelli, S., C. Piromallo and E. Serpelloni (2004b): Convergence versus retreat in southern Tyrrhenian Sea: insights from kinematics, Geophys. Res. Lett., 31, L06611, doi: 10.1029/2003GL019223.

Pondrelli, S., S. Salimbeni, G. Ekström, A. Morelli, P. GAsperini and G. VANNUCCI (2006): The Italian CMT dataset from 1977 to the present, Phys. Earth Planet. Int., 159, 286-303.

Pondrelli, S., S. Salimbeni, A. Morelli, G. Ekström and E. BosCHI (2007): European-Mediterranean Regional Centroid Moment Tensor catalogue: solutions for years 2003-2004, Phys. Earth Planet., 164, 90-112.

Rebaï, S., H. PhiliP and A. TABoAda (1992): Modern tectonics stress field in the Mediterranean region: Evidence for variation in stress directions at different scales, Geophys. J. Int., 110, 106-140.

Serpelloni E., G. Vannucci, S. Pondrelli, A. Argnani, G. CAsula, M. AnZidei, P. BAldi and P. GAsperini (2007): Kinematics of the western Africa-Eurasia plate boundary from focal mechanisms and GPS data, Geophys. J. Int., doi: 10.1111/j.1365-246X.2007.03367.x

Vannucci, G., S. Pondrelli, A. Argnani, A. Morelli, P. GASPERINI and E. Boschi (2004): An atlas of Mediterranean seismicity, Ann. Geophys., 47, 247-306.

VANNUCCI, G. and P. GASPERINI (2004): The new release of the database of Earthquake Mechanisms of the Mediterranean Area (EMMA Version 2), Ann. Geophys., $\mathbf{4 7}$, suppl. to n. 1 .

WESTAWAY, R. (1992): Seismic moment summation for historical earthquakes in Italy: tectonic implications, $J$. Geophys. Res., 97, 15,437-15,464.

Zoвack, M. L. (1992): First- and second-order patterns of stress in the lithosphere: The World Stress Map Project, J. Geophys. Res., 97, 11703-11728. 